\title{
MONITORING KELEMBABAN TANAH PERTANIAN MENGGUNAKAN SOIL MOISTURE SENSOR FC-28 DAN ARDUINO UNO
}

\author{
Husdi \\ Mr.husdi@yahoo.com \\ Universitas Ichsan Gorontalo
}

\begin{abstract}
Abstrak
Tanah sebagai faktor utama dalam pertanian harus dipertimbangkan sebaik mungkin agar dapat memberikan hasil seperti yang diharapkan. Salah satunya dengan memanfaatkan teknologi komputer dan internet untuk memonitor kelembaban tanah. Kelembaban tanah adalah salah satu faktor lingkungan yang mempengaruhi pertumbuhan tanaman. Salah satu inovasi teknologi informasi dan komunikasi di bidang pertanian adalah penggunaan Internet of Things. Dengan menggunakan Internet Of Things, hal itu bisa dilakukan untuk memantau kelembaban tanah yang menjadi media tanam tanaman hortikultura. mengetahui nilai kelembaban tanah akan sangat berguna untuk dapat menentukan langkah atau penanganan tanah. Hasil pengujian menunjukkan bahwa pengukuran kelembaban tanah menggunakan sensor kelembaban tanah dapat bekerja dengan baik dan menampilkan informasi nilai kelembaban tanah. Berdasarkan hasil dan analisis yang telah dilakukan, dapat disimpulkan bahwa hasil pemantauan sistem pemantauan kelembaban tanah ini sudah dapat digunakan untuk memonitor lahan pertanian. Sehingga hasil penelitian ini diharapkan dapat membantu petani dalam pengambilan keputusan berdasarkan informasi tentang nilai kelembaban tanah yang telah diperoleh. Hasil akhir yang didapatkan dari pembacaan nilai sensor adalah basah, lembab dan kering sesuai dengan nilai range Data Analog yang telah ditetapkan. Yaitu Kondisi basah ketika mendapatkan keluaran dengan range batas bawah yaitu 150 dan batas atas 339, kondisi lembab ketika mendapatkan keluaran dengan range batas bawah 340 batas atas 475 , kondisi Kering ketika mendapatkan nilai sensor dengan range batas bawah yaitu 476 dan batas atas 1023 .

Kata Kunci: Kelembaban Tanah, Sensor, Arduino
\end{abstract}

Land as the main factor in agriculture must be considered as well as possible in order to provide the expected results. One of them is by using computer and internet technology to monitor soil moisture. Soil moisture is one of the environmental factors that affect plant growth. One of the innovations in information and communication technology in agriculture is the use of the Internet of Things. By using the Internet of Things, it can be done to monitor soil moisture that is used as a planting medium for horticultural crops. knowing the value of soil moisture will be very useful to be able to determine the steps or handling of the soil. The test results show that the measurement of soil moisture using a soil moisture sensor can work well and display information on the value of soil moisture. Based on the results and analysis, it can be concluded that the results of monitoring the soil moisture monitoring system can already be used to monitor agricultural land. So that the results of this study are expected to help farmers in making decisions based on information about the value of soil moisture that has been obtained. The final result obtained from the reading of the sensor value is wet, moist and dry according to the set value of the Analog Data. That is wet condition when getting output with lower limit range of 150 and upper limit of 339, humid condition when getting output with lower limit range 340 upper limit of 475 , dry condition when getting sensor value with lower limit range is 476 and upper limit is 1023.

Keywords: Soil moisture, Sensor, Arduino

\section{Pendahuluan}

Perkembangan teknologi informasi dan komunikasi sekarang ini sudah hampir digunakan pada berbagai bidang tak terkecuali pada bidang pertanian. Indonesia sebagai negara agraris dengan sumber daya alam yang besar harus diolah secara maksimal. Tanah sebagai faktor utama dalam holtikultura harus diperhatikan dengan sebaik-baiknya agar dapat memberikan hasil sesuai dengan yang diharapkan. Salah satunya dengan cara memanfaatkan teknologi komputer dan internet untuk memonitor kelembaban tanah.

Salah satu permasalahan yang dialami oleh petani khususnya di Kabupaten Bone Bolango Provinsi Gorontalo adalah kesulitan memonitoring kelembaban tanah yang menjadi media tanam untuk tanaman holtikultura dengan menggunakan inovasi Teknologi Informasi, sehingga nantinya informasi yang dihasilkan bisa digunakan untuk pengambilan keputusan dalam mengelolah 
pertaniannya. Tujuan jangka panjang sebagai pengembangan dari penelitian ini adalah dengan adanya transmisi data secara Real Time maka akan tercipta sebuah Bank Data (Data Base) yang nantinya akan bisa dilanjutkan pada penelitian Data Mining, Sistem Cerdas, Big Data, dsb.

Rendahnya rata-rata curah hujan yang terjadi di Provinsi Gorontalo dalam setahun mempengaruhi kelembaban tanah. Dengan monitoring kelembaban tanah maka pengendalian terhadap kadar air yang ada dalam tanah dapat dilakukan sehingga dapat memberikan hasil panen sesuai dengan yang diharapkan. Hal ini sejalan dengan cita-cita pemerintah provinsi Gorontalo yakni menjadi Smart City dan Smart Farm sehingga inovasi teknologi dalam berbagai bidang perlu dilakukan

Inovasi teknologi informasi dan komunikasi dalam bidang pertanian adalah penggunaan sensor dan Mikrokontroller. Dengan menggunakan peralatan teknologi informasi dan komunikasi maka dapat dilakukan monitoring terhadap kelembaban tanah yang menjadi media tanam dari tanaman Pertanian. mengetahui nilai kelembaban tanah akan sangat bermanfaat untuk bisa menentukan langkah atau penanganan terhadap tanah tersebut. Jika kelembaban tanah kurang dari ambang batas yang dibutuhkan oleh tanaman holtikultura tersebut maka secara otomatis akan dilakukan penyiraman. Pengguanan Peralatan sensor yang terintegrasi dengan web server sehingga memungkinkan untuk monitoring dan pengontrolan jarak jauh. Dengan menggunakan Arduino UNO sebagai pengendali utama yang diprogram untuk mengetahui kelembaban tanah tanaman melalui Soil Moisture Sensor FC-28 yang ditanam di tanah dan hasil kelembaban tanah akan ditampilkan secara online.

Rumusan masalah dalam penelitian ini adalah bagaimana sulitnya monitoring kelembaban tanah pada tanaman holtikultura secara realtime sehingga informasi yang dihasilkan bisa digunakan untuk pengambilan keputusan dalam mengelolah pertaniannya. Adapun Tujuan dari penelitian ini adalah.Untuk memonitoring nilai kelembaban tanah untuk pengambilan keputusan dalam mengelolah pertanian

\section{Metode}

\subsection{Internet of Things (IoT).}

Internet of Things (IOT) pertama kali diperkenalkan oleh Kevin Ashton pada tahun 1999. Meski telah diperkenalkan sejak 15 tahun yang lalu, hingga kini belum ada sebuah konsensus global mengenai definisi IoT. Namun secara umum konsep loT diartikan sebagai sebuah kemampuan untuk menghubungkan objek-obek cerdas dan memungkinkannya untuk berinteraksi dengan objek lain, lingkungan maupun dengan peralatan komputasi cerdas lainnya melalui jaringan internet. IoT dalam berbagai bentuknya telah mulai diaplikasikan pada banyak aspek kehidupan manusia. CISCO bahkan telah menargetkan bahwa pada tahun 2020, 50 miliar objek akan terhubung dengan internet[1]

Meluasnya adopsi berbagai teknologi $I o T$, membuat kehidupan manusia menjadi jauh lebih nyaman. Dari sisi pengguna perorangan, IOT sangat terasa pengaruhnya dalam bidang domestik seperti pada aplikasi rumah dan mobil cerdas. Dari sisi penguna bisnis, IoT sangat berpengaruh dalam meningkatkan jumlah produksi serta kualitas produksi, mengawasi distribusi barang, mencegah pemalsuan, mempersingkat waktu ketidak tersedian barang pada pasar retail, manajemen rantai pasok, dsb [1]

\subsection{Sensor Kelembaban tanah.}

Soil moisture sensor FC-28 adalah sensor kelembaban yang dapat mendeteksi kelembaban dalam tanah. Sensor ini sangat sederhana, tetapi ideal untuk memantau taman kota, atau tingkat air pada tanaman pekarangan. Sensor ini terdiri dua probe untuk melewatkan arus melalui tanah, kemudian membaca resistansinya untuk mendapatkan nilai tingkat kelembaban. Semakin banyak air membuat tanah lebih mudah menghantarkan listrik (resistansi kecil), sedangkan tanah yang kering sangat sulit menghantarkan listrik (resistansi besar). Sensor ini sangat membantu untuk mengingatkan tingkat kelembaban pada tanaman atau memantau kelembaban tanah. [2]

Soil moisture sensor FC-28 memiliki spesifikasi tegangan input sebesar $3.3 \mathrm{~V}$ atau $5 \mathrm{~V}$, tegangan output sebesar $0-4.2 \mathrm{~V}$, arus sebesar $35 \mathrm{~mA}$, dan memiliki value range ADC sebesar 1024 bit mulai dari 0 - 1023 bit. Adapun gambar soil moisture sensor FC-28 dapat dilihat pada gambar 1 . 


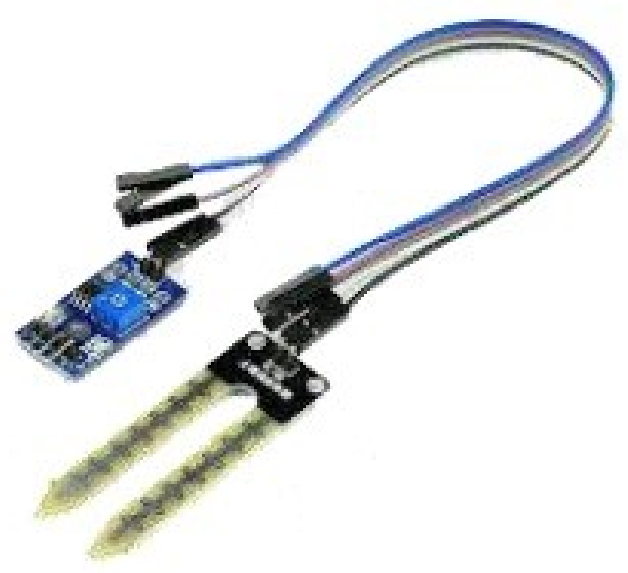

Gambar 1. Soil Moisture Sensor FC-28

Prinsip kerja moisture sensor pada alat ini adalah dengan menanamkan satu buah sensor kelembaban pada tanah. Kerja sensor ini mendeteksi adanya tingkat kelembaban. Kelembaban tersebut disetting dengan parameter khusus, sehingga ketika kelembaban tersebut sesuai, maka tanah longsor dipastikan akan terjadi. [3]

\subsection{Arduino}

Arduino UNO merupakan board mikrokontroler yang menggunakan mikrokontroler ATmega328, Arduino UNO memiliki konfigurasi 14 pin I/O (Input Output) digital, yang sebagian 6 juga berfungsi sebagai PWM (Pulse Widht Modulator) untuk output analog , 6 Pin sebagai input analog, 1 pin RX-TX dan 1 pin AREF (Analogue Reference). [4]

Dengan menghubungkannya ke sebuah komputer melalui USB akan memberikan tegangan Direct Current (DC) dari baterai atau adaptor Alternating Current (AC) to DC Sebagai sumber tegangan untuk arduino. Arduino menggunakan Firmware ATmega16U2 yang diprogram sebagai USB to serial converter untuk komunikasi serial ke komputer melalui port USB. Arduino UNO dapat dilihat pada gambar 2.2 berikut ini:[4]

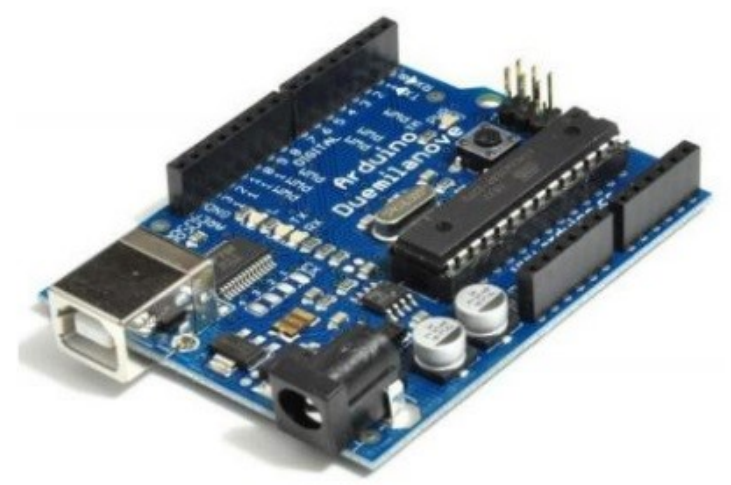

Gambar 2. Arduino UNO Board

Kelebihan Arduino diantaranya adalah tidak perlu perangkat chip programmer karena didalamnya sudah ada bootloader yang akan menangani upload program dari komputer, Arduino sudah memiliki sarana komunikasi USB, sehingga pengguna laptop yang tidak memiliki port serial/RS323 bisa menggunakannya. Bahasa pemrograman relatif mudah karena software Arduino dilengkapi dengan kumpulan library yang cukup lengkap, dan Arduino memiliki modul siap pakai (shield) yang bisa ditancapkan pada board Arduino. Misalnya shield GPS, Ethernet, SD Card, dll.[5]

\subsection{Model Yang Di Usulkan}

Model yang digunakan untuk rangkaian dan menjalankan program arduino. Adapaun Model yang digunakan dalam penelitian ini adalah sebagai berikut: 


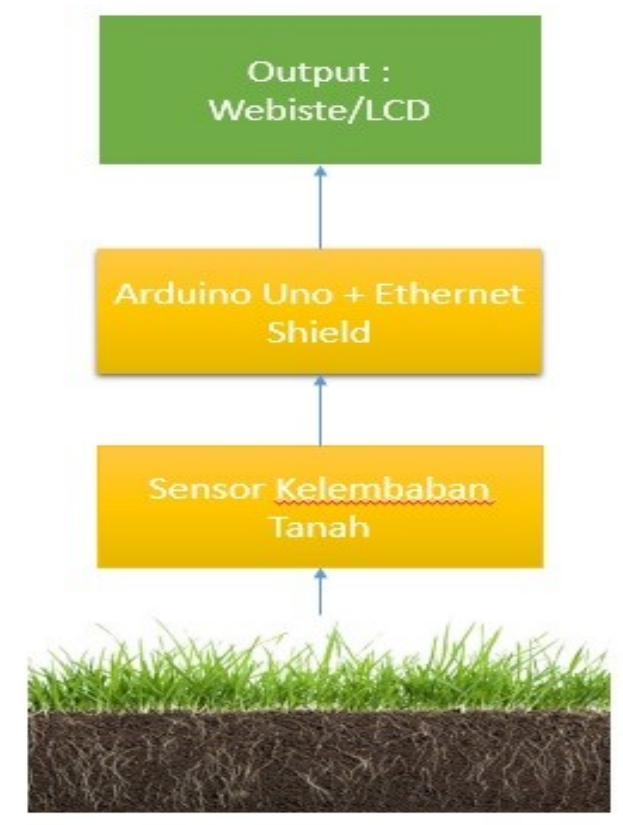

Gambar 3. Model Yang di gunakan

Pada gambar 3 di atas terdapat blok diagram model yang digunakan pada penelitian ini dijelaskan bahwa tanah sebagai media tanam akan diukur kelembabannya dengan menggunakan sensor kelembaban tanah Soil moisture sensor FC-28 selanjutnya dari sensor tersebut didapatkan nilai kelembaban tanah yang akan diteruskan ke arduino uno sebagai mikrokontroller selanjutnya dari arduiono Uno akan disambungkan dengan webserver. Dengan adanya transmisi data secara real time tersebut pengembangan dari penelitian ini diharapkan dapat bermanfaat jika dilakukan pada daerah yang luas atau untuk kecepatan pengambilan keputusan walaupun tidak berada pada area atau lokasi budidaya tanaman holtikultura. Sehingga dapat mengefisienkan waktu dan tenaga pemilik tanaman dalam melakukan aktivitasnya tanpa mengurus langsung tanaman yang dimiliki. Salah satu contoh adalah dengan adanya pemantauan kelembaban tanah tersebut maka dapat juga dilakukan pengontrolan alat penyiraman tanaman walaupun tidak berada di lokasi tersebut

\subsection{Desain Rangkaian}

Pada penelitian ini terdapat beberapa komponen dan modul yang dibutuhkan yaitu:

1. Mikrokontroller Arduino Uno

Mikrokontroler Arduino Uno berfungsi sebagai pusat pengolah data atau dapat dikatakan sebagai CPU (Central Proccesing Unit), yang mana tugasnya mengolah semua data yang masuk dan data yang keluar. Bagian ini akan memeriksa input dari keypad berupa kode password, dan memberikan perintah ke bagian LED, dan relay [5]

2. Sensor Kelembanan Tanah (Soil Moisture Sensor)

Soil Moisture Sensor berfungsi sebagai sensor untuk membaca nilai kelembaban tanah dengan cara mencapkan di tanah yang akan diukur

3. Ethernet Shield Arduino

Ethernet Shield Arduino berfungsi untuk mengkoneksikan arduino dengan internet menggunakan kabel LAN

4. LCD Keypad Shield For Arduino

LCD Keypad Shield For Arduino berfungsi untuk menampilkan hasil pembacaan sensor

5. Kabel Jumper

Kabel Jumper Secukupnya untuk menghubungkan pin pin pada sensor kelembaban tanah, Arduino, dsb

6. Kabel $L A N$

Kabel LAN berfungsi untuk menghubungkan Ethernet shield dengan $\mathrm{PC} /$ laptop

\subsection{Desain Perangkat Keras Keselurahan.}

Modul-modul dan komponen eletronika tersebut dirangkai dengan menggunakan kabel jumper. Untuk desain rangkaiannya dapat di lihat pada gambar 4 sebagai berikut: 


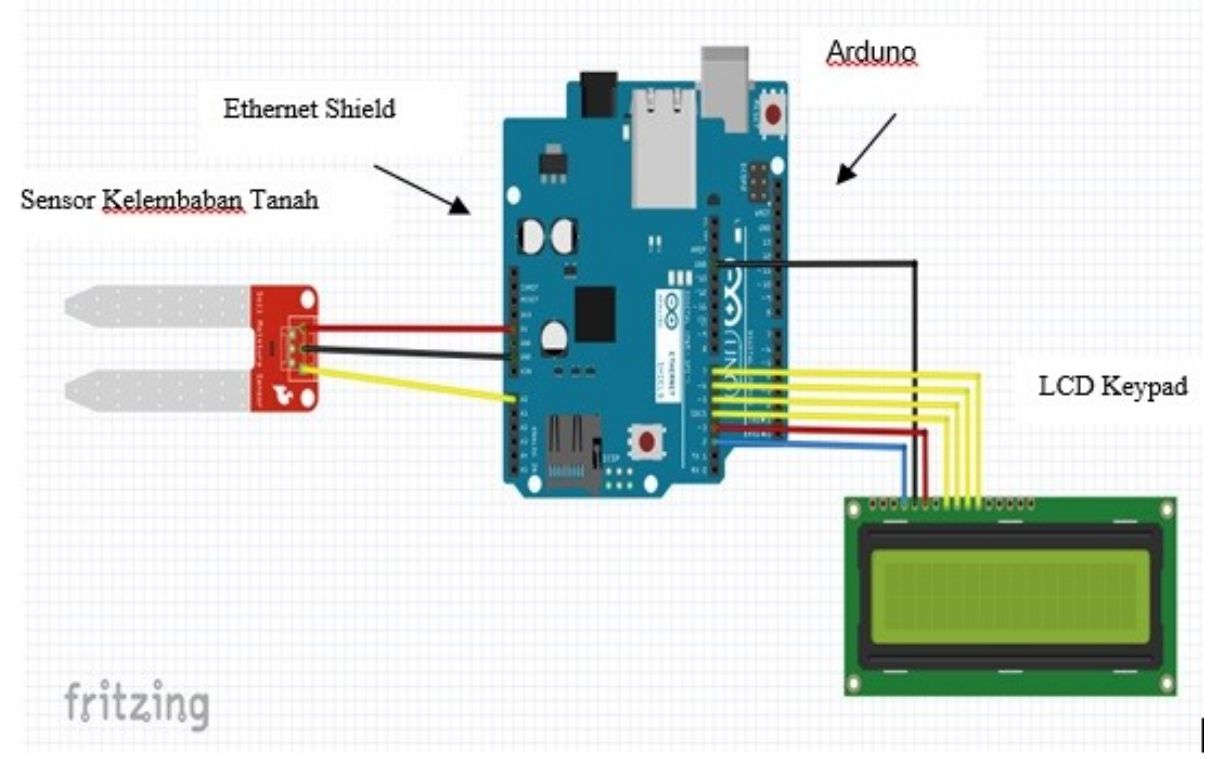

Gambar 4. Desain perangkat Keras Secara Keseluruhan

\section{Hasil dan Pembahasan}

Bahasa pemograman untuk memprogram arduino menggunakan bahasa C. Untuk membuat program dan mengupload program ke dalam mikrokontroler dibutuhkan sebuah software yaitu Arduino IDE (Integrated Development Environment). Setelah perangkat keras selesai dibangun maka tahapan selanjutnya adalah mengupload sketch Program yang telah dibuat ke modul Arduino uno.

Pengujian alat secara keseluruhan sudah meliputi pengujian hardware dan software. Pengujian dilakukan dengan meletakkan sensor soil moisture dan menancapkan sensor ke tanah. Pengujian dilakukan dengan mengirimkan nilai kelembaban tanah dengan sensor soil moisture Kepada Arduino yang selanjutnya ditransmisikan ke layar komputer.

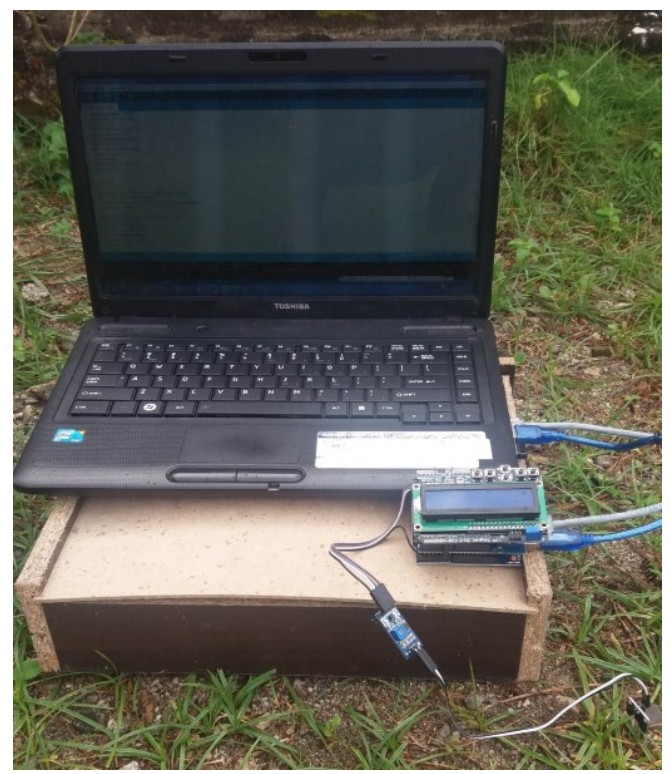

Gambar 5. Pengujian Perangkat Pada Tanah

Sedangkan untuk tampilan halaman website yang akan digunakan menampilkan hasil pembacaan sensor adalah sebagai berikut. 


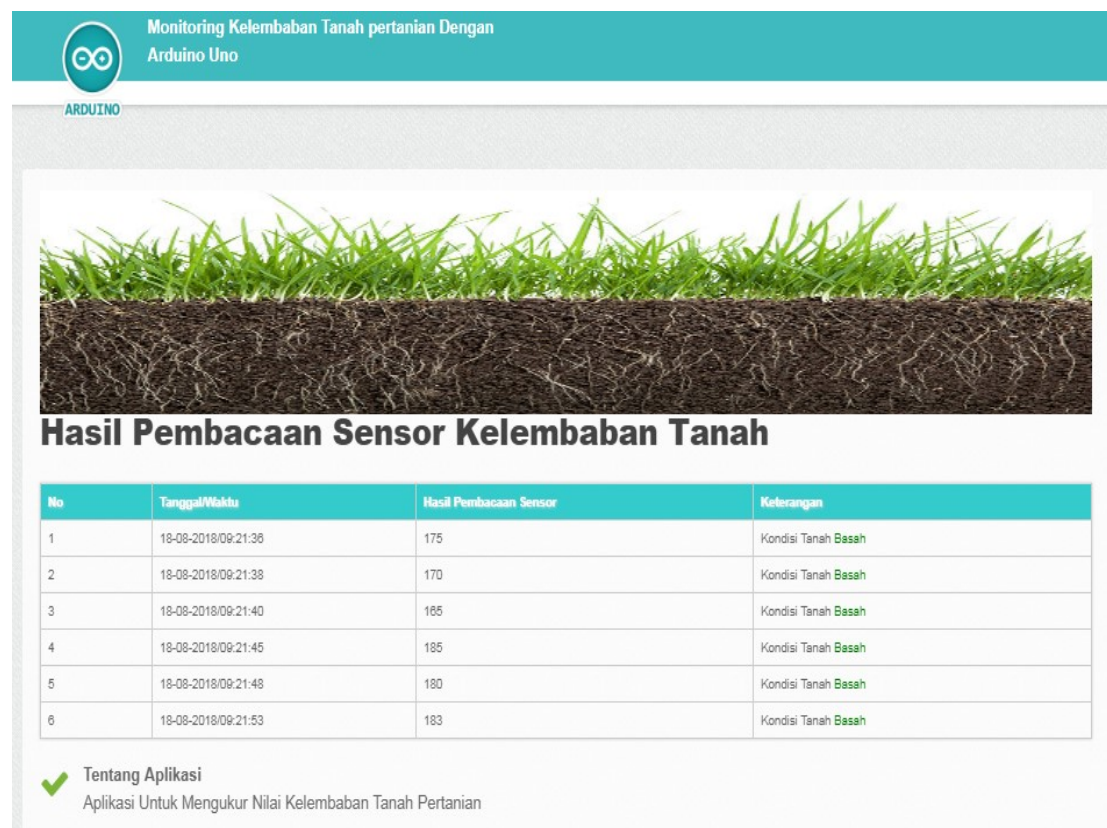

Gambar 6. Hasil Pembacaan Sensor Kelembaban Tanah

Hasil dari pengukuran nilai kelembaban tanah akan menghasilkan nilai range batas dari basah, lembab dan kering. Kondisi basah ketika mendapatkan keluaran dengan range batas bawah yaitu 150 dan batas atas 339, kondisi lembab ketika mendapatkan keluaran dengan range batas bawah 340 batas atas 475 , kondisi Kering ketika mendapatkan nilai sensor dengan range batas bawah yaitu 476 dan batas atas 1023.[6]

Hasil pengujian pada menunjukkan bahwa pengukuran kelembaban tanah menggunakan sensor soil moisture dapat bekerja dengan baik dan menampilkan informasi nilai kelembaban tanah setelah dilakukan beberapa kali pengujian sebagai berikut.

Tabel 1. Pengujian Sistem

\begin{tabular}{|l|l|l|l|l|}
\hline No & Tanggal Pengujian & $\begin{array}{c}\text { Rata-Rata Nilai Data } \\
\text { Analog (DA) Sensor }\end{array}$ & Nilai Range & Keterangan \\
\hline 1 & $15-08-2018$ & DA 520 s/d DA 550 & Kondisi Kering & Sesuai \\
\hline 2 & $18-08-2018$ & DA 520 s/d DA 590 & Kondisi Kering & Sesuai \\
\hline 3 & $20-08-2018$ & DA 560 s/d DA 650 & Kondisi Kering & Sesuai \\
\hline 4 & $22-08-2018$ & DA 140 s/d DA185 & Kondisi Basah & Sesuai \\
\hline 5 & $23-08-2018$ & DA 360 s/d DA 400 & Kondisi Lembab & Sesuai \\
\hline
\end{tabular}

Pengujian yang telah dilakukan pada tanggal yang berbeda didapatkan kondisi kelembaban tanah sesuai dengan nilai rata-rata Data Analog sensor sebagai berikut:

1. Nilai DA 520 s/d DA 550, DA 520 s/d DA 590 dan DA 560 s/d DA 650 maka kondisi tanah adalah kering. Hal tersebut sesuai dengan pengamatan pada lokasi penelitian yaitu kondisi tanah sangat kering,

2. Nilai DA $140 \mathrm{~s} / \mathrm{d}$ DA 185 maka kondisi tanah adalah basah hal tersebut sesuai dengan pengamatan pada lokasi penelitian yang sedang berlangsung hujan, dan

3. Nilai DA $360 \mathrm{~s} / \mathrm{d}$ DA 400 maka kondisi tanah adalah Lembab hal tersebut sesuai dengan pengamatan pada lokasi penelitian karena pengujian dilakukan 1 hari setelah hujan turun

Berdasarkan hasil dan analisis yang telah dilakukan, dapat disimpulkan bahwa hasil rancagan sistem monitoring kelembaban tanah dapat digunakan untuk memonitoring lahan pertanian. Sehingga hasil penelitian ini diharapkan dapat dikembangkan untuk membantu petani dalam pengambilan keputusan berdasarkan informasi nilai kelembaban tanah yang telah diperoleh. Apabila nilai keluaran yang ditampilkan menghasilkan keterangan kering maka perlu untuk dilakukan penyiraman atau pengairan pada lahan tersebut. Sebaliknya jika nilai range yang dihasilkan adalah basah maka perlu untuk memperhatikan irigasi untuk menjaga kelembaban tanah pertanian tersebut 


\section{Kesimpulan dan Saran}

\subsection{Kesimpulan}

Berdasarkan hasil dan analisis yang telah dilakukan, dapat disimpulkan bahwa hasil rancangan sistem monitoring kelembaban tanah ini dapat digunakan untuk memonitoring lahan pertanian dengan kondisi tanah yang dihasilkan adalah basah, lembab dan kering. Dari hasil pengujian yang telah dilakukan pengukuran kelembaban tanah dengan menggunakan sensor Soil Moisture dapat mengirimkan dengan baik nilai kelembaban tanah ke arduino dan ditransmisikan ke layar komputer dan $L C D$. Jika kondisi tanah dalam keadaan kering maka nilai range yang ditampilkan di akan tinggi atau tanah dalam kondisi kering. Demikian kian juga sebaliknya pada saat hujan turun atau tanah dalam keadaan basah maka nilai range yang dihasilkan akan rendah atau tanah dalam keadaan basah dan lembab. Kondisi basah ketika mendapatkan keluaran dengan range batas bawah yaitu 150 dan batas atas 339 , kondisi lembab ketika mendapatkan keluaran dengan range batas bawah 340 batas atas 475 , kondisi Kering ketika mendapatkan nilai sensor dengan range batas bawah yaitu 476 dan batas atas 1023 .

\subsection{Saran}

Sesuai dengan batasan dan hasil dari penelitian ini bahwa penelitian ini hanya sampai pada batas monitoring kelembaban tanah sehingga perlu dilanjutkan pada penggunaan kontrol otomatis dan penambahan machine learning pada aplikasi yang telah berdasarkan informasi kelembaban tanah yang ditransmisikan.

\section{Daftar Pustaka}

[1] E. D. Meutia, "Internet of Things - Keamanan dan Privasi," Semin. Nas. dan Expo Tek. Elektro 2015, pp. 85-89, 2015.

[2] L. . F. A. Caesar Pats Yahwe, Isnawaty, "Rancang Bangun Prototype System Monitoring Kelembaban Tanah Melalui Sms Berdasarkan Hasil Penyiraman Tanaman System Monitoring Kelembaban Tanah Melalui Sms Berdasarkan Hasil Penyiraman Tanaman," semanTIK, vol. Vol 2, no. 1, pp. 97-110, 2016.

[3] V. V. Verdi, E. Kurniawan, F. T. Elektro, and U. Telkom, "Desain Dan Implementasi Sistem Pengukuran Kelembapan Tanah Menggunakan Sms Gateway Berbasis Arduino Design and Implementation of Soil Moisture Measurement," vol. 2, no. 3, pp. 7004-7010, 2015.

[4] Kurniawan, "Purwarupa loT (Internet Of Things) Kendali Lampu Gedung (Studi Kasus Pada Gedung Perpustakaan Universitas Lampung)," vol. 57, 2016.

[5] E. H. Helmi guntoro, Yoyo Somantri, "Rancang Bangun Magnetic Door Lock Menggunakan Keypad Dan Solenoid Berbasis Mikrokontroler Arduino Uno," Electrans, vol. 12, no. 1, pp. 3948, 2013.

[6] R. Wijaya, S. Hardienata, and A. Chairunnas, "Model Pengukur Kelembaban Tanah Untuk Tanaman Cabai Menggunakan Sensor Kelembaban Tanah Dengan Tampilan Output Web Server Berbasis Mikrokontroler ATMega328," Univ. Pakuan, 2016. 